International Journal of Engineering \& Technology, $7(2.31)(2018) 4-8$
International Journal of Engineering \& Technology
SPC
Website: www.sciencepubco.com/index.php/IJET
Research paper

\title{
Design and simulation of low actuation voltage RF MEMS shunt capacitive switch with serpentine flexures\&rectangular perforations
}

\author{
K. Jayavardhani ${ }^{1 *}$, S.K. Noureen Fathima ${ }^{2}$, K. Bhima Sankar ${ }^{3}$, K. Kavya Sri ${ }^{4}$, S. Sunithamani ${ }^{5}$ \\ ${ }^{I}$ Department of ECE, Koneru Lakshmaiah Education Foundation, Vaddeswaram, Guntur, Andhra Pradesh, India. \\ ${ }^{2}$ Department of ECE, Koneru Lakshmaiah Education Foundation, Vaddeswaram, Guntur, Andhra Pradesh, India. \\ ${ }^{3}$ Department of ECE, Koneru Lakshmaiah Education Foundation, Vaddeswaram, Guntur, Andhra Pradesh, India. \\ ${ }^{4}$ Department of ECE, Koneru Lakshmaiah Education Foundation, Vaddeswaram, Guntur, Andhra Pradesh, India \\ ${ }^{5}$ Department of ECE, Koneru Lakshmaiah Education Foundation, Vaddeswaram, Guntur, Andhra Pradesh, India. \\ *Corresponding author E-mail:14004046@kluniversity.in
}

\begin{abstract}
This paper presents the design and simulation of RF MEMS shunt capacitive switch with low actuation voltage, low insertion loss and high isolation. Actuation voltage depends on the parameters like air gap, spring constant and actuation area. In this design, we have proposed a serpentine meander structure to reduce the spring constant of the beam thus reducing actuation voltage. The rectangular perforation is used to reduce the squeeze film damping by decreasing the mass of the switch. The proposed switch has attained a low actuation voltage of $4.5 \mathrm{~V}$ for a displacement of $0.84 \mu \mathrm{m}$. The air gap between the beam and the dielectric is $1 \mu \mathrm{m}$. This radio frequency (RF) MEMS shunt switch is designed and simulated using COMSOL Multiphysics 5.2. The RF performance of the shunt switch is analyzed in Ansoft HFSS 13 and the results show that the return loss was about $-13.50 \mathrm{~dB}$ at $20 \mathrm{GHz}$ in the OFF state and $-8.5 \mathrm{~dB}$ at 18 $\mathrm{GHz}$ in the $\mathrm{ON}$ state. A high isolation of $-36.00 \mathrm{~dB}$ was achieved in the OFF state at a frequency of $5 \mathrm{GHz}$ and a low insertion loss is obtained. The results show that the switch is suitable for wireless applications operating in the frequency range from 5 to $20 \mathrm{GHz}$.
\end{abstract}

Keywords: Actuation voltage, serpentine structure, MEMS switch, spring constant.

\section{Introduction}

MEMS imply Micro Electro Mechanical Systems. It is a smallscale machine that has both mechanical (springs, levers) and electrical segments (resistors, capacitors, inductors). The electrical and mechanical systems are integrated on a single silicon substrate The components of MEMS are scaled miniaturized sensors, structures and actuators. MEMS are comprised of parts in between 1 and 100 micrometers in size. The incorporated electrical and mechanical components in MEMS are utilized for various applications from display technologies to sensor frameworks to optical systems. In view of their small size they have less weight and cost and they can be fit in any place. RF refers to radio frequencies. The radio frequencies range from $3 \mathrm{KHz}$ to $300 \mathrm{GHz}$. The RF MEMS are those small-scale devices that can be utilized for radio frequency applications. RF MEMS have numerous helpful applications particularly in radars, remote, wireless and communication systems. Different RF MEMS parts are RF MEMS switches, RF MEMS tunable inductors, switched capacitors, varactors and Filters. F-MEMS (Radio Frequency Micro Electro Mechanical Systems)switches are the one which replaces the convectional GaAs FET and PIN diode switches in Radio frequency communication because of their low cost, low power utilization, low insertion loss, high isolation, ultra-wide frequency band and because of its linearity and intermodulation practices(Rebeiz and Muldavin 2001).MEMS switch can be classified based on mechanical structure as cantilever beam, fixedfixed beam and diaphragm, actuation mechanism as electrostatic and electrothermal, contact type as resistive and capacitive, RF circuit configuration as series and shunt. The structure of cantilever beam is generally utilized for design of series switches, Fixed-Fixed type of beam is utilized for shunt switches. Series switches are used for low frequency range (gigahertz) and shunt switches are used for high gigahertz applications. The spring constant is high in fixed-fixed beam when compared with cantilever beam. The diaphragm structure is mainly used as MEMS pressure sensor. Among the actuation mechanisms, the electrostatic actuation mechanism is the most widely recognized technique because of its simplicity and low consumption. In the capacitive switches, the transmission signal is a radio frequency signal. When a switch is in the upstate, the signal cannot cross through CPW line. By applying an electrical voltage, the switch is closed, and the signal is transmitted through the switch to the ground. In fact, in the capacitive switches, ON or OFF state is obtained by a change in the capacitance value between movable switching and signal transmission line. Resistive contact switches utilize metal to metal contact for ohmic contact between signal line and contact beam. For series switch operation initially, the switch is in off state, when an actuation voltage is applied the switch will be on and signal transfers from input to output. The parameters that can be considered in MEMS switches are transition time, spring constant, RF power handling, switching transients, bandwidth, insertion loss, isolation, switch resistance, Actuation voltage, Life time of switch, resonant frequency. The main aim is to design a switch with low actuation voltage by overcoming various difficulties such as low power handling capability, low isolation, insufficient reliability, large transition 
time and high insertion loss. To obtain low actuation voltage without effecting the RF performance of the switch the parameters such as spring constant and air gap must be decreased, and the actuation area must be increased.

In this paper, a shunt capacitive switch with a fixed-fixed beam structure and with electrostatic actuation mechanism is designed. Specifically, gold is used in the design of beam and CPW lines because of its high conductivity. This paper is organized as follows. In section II, the design, working principle and the parameters of the switch are clearly reported. Finally, in section III, the results of the switch displacement, its RF performance is presented, and the proposed switch parameters are compared with the results of previous papers.

\section{Design and working principle}

\section{Working principle}

The capacitive shunt switch consists of bridge, CPW line, dielectric layer and substrate. The shunt switch has a thin metallic bridge structure suspended over the CPW line. The bridge structure is supported by two anchors which are connected to the CPW lines. A dielectric layer is present on the signal line. When no actuation voltage is applied on the beam, the shunt switch is in 'ON' state. The signal flows from input to output. When an actuation voltage is applied on the beam, the electrostatic force moves the beam on to the dielectric layer. When the beam touches the dielectric layer, which is present on the signal line then the switch is said to be in 'OFF' state. There will be a short circuit and no signal flows from input to output. The side view of a shunt capacitive switch is shown in Fig 1.

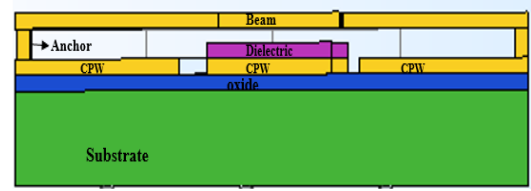

Fig. 1: Structure of MEMS shunt switch

\section{Design of proposed switch}

The proposed switch is designed over a silicon substrate with dimensions $370 \mu \mathrm{m}$ length, $200 \mu \mathrm{m}$ width, $60 \mu \mathrm{m}$ height. An oxide layer of thickness $0.1 \mu \mathrm{m}$ is placed over the substrate. Silicon dioxide material is used for the oxide layer. Gold $(\mathrm{Au})$ material is used in the design of coplanar waveguide (CPW) lines.The thickness of CPW lines is $0.1 \mu \mathrm{m}$. Silicon Nitride $\left(\mathrm{Si}_{3} \mathrm{~N}_{4}\right)$ is used as dielectric material between the beam and the signal line, with dielectric constant of 9.7 and a thickness of $0.1 \mu \mathrm{m}$. Siliconnitride is selected as di-electricas it is having high di-electric constant, high thermal conductivity. The bridge is designed with three blocks and serpentine meanders by using gold $(\mathrm{Au})$ material with thickness $1 \mu \mathrm{m}$. The rectangular holes that are formed in the actuation structure are uniform, they reduce the mass of the beam. The dimension of each hole is $1 \mu \mathrm{m}$ width and $3 \mu \mathrm{m}$ length. The holes also improve the efficiency of the switch by decreasing the air damping and switching time. A bridge structure is arranged over the dielectric with a gap of $1 \mu \mathrm{m}$. Two anchors are placed at the two ends to support the beam. Gold is used in the design of the two anchors. The 3D structure of the switch is shown in Fig 2.The switch dimensions are shown in Table 1 and Fig 3.

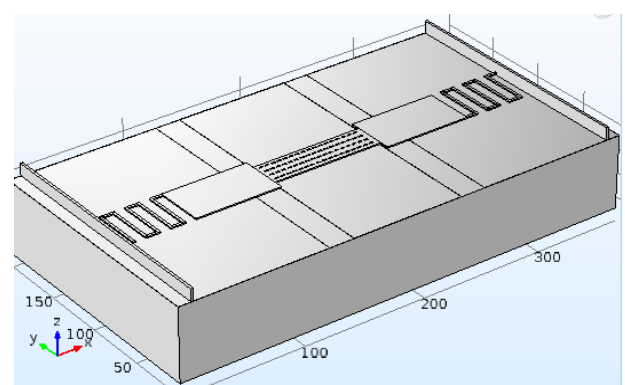

Fig. 2: 3D structure of the switch

Table 1: Switch Parameters

\begin{tabular}{lc}
\hline Parameter & Dimensions $(\mu \mathrm{m})$ \\
\hline Silicon Substrate & $370 \times 200 \times 60$ \\
Oxide Thickness & 0.1 \\
Thickness of CPW lines & 0.1 \\
Dielectric layer thickness & 0.1 \\
Gapbetween beam and Dielectric & 1 \\
layer & \\
Overlap area & $90 \times 25$ \\
Dielectric thickness & 0.1 \\
Dielectric Constant & 9.7 \\
Beam thickness & 1 \\
\hline
\end{tabular}

\section{Actuation voltage}

Actuation voltage is that which is used to activate the switch. Actuation voltage can be achieved for the switches by using various mechanism methods like electrostatic, thermal, piezoelectric and magnetic. Commonly used actuation mechanism is electrostatic actuation because of its almost negligible power consumption, minute size and low switching time. Actuation voltage can be reduced by overcoming difficulties like low power dissipation, low actuation, insufficient reliability, more insertion loss and high transition time. To decrease actuation voltage of RF MEMS switches we can decrease air gap, decrease spring constant and can increase electrostatic field area. A minute changes in these three parameters effect the other parameters of actual switch like insertion loss and return loss. Other way to reduce actuation voltage is to decrease the spring constant. Isolation of metal contact switches is mainly affected while reducing actuation voltage. The pull in voltage is the voltage for which the beam touches the dielectric.

$\mathrm{V}_{\mathrm{p}}=\sqrt{\frac{8 K g_{0}^{3}}{27 A \epsilon_{0}}}$

Where $\mathrm{A}$ is actuation area, $\mathrm{g}_{0}$ is the air gap, $\mathrm{K}$ is spring constant.

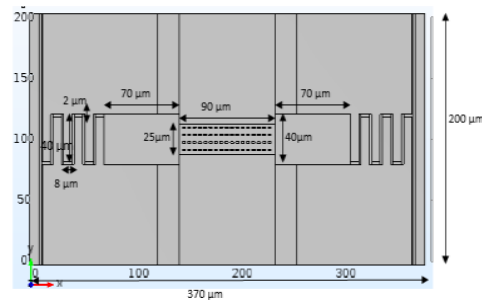

Fig. 3: Dimensions of switch

As the spring constant is proportional to the pull in voltage, by reducing the spring constant we can reduce the pull in voltage. The pull in voltage can also be reduced by decreasing the air gap and increasing the actuation area. The actuation voltage can be decided by the spring constant. The spring constant can be written as:

$\mathrm{K}=\frac{E W t^{3}}{l^{3}}$ 
where W width, E young's modules, $\mathrm{t}$ is thickness, 1 is the length of beam.

The structure of meander used for this design is serpentine meander structure. The meander structure used in the proposed switch is shown in Fig 4.

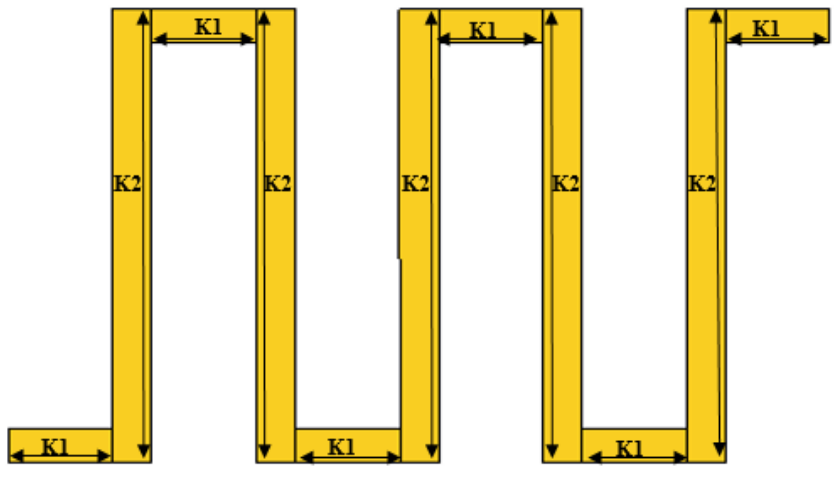

Fig. 4: Meander with spring constants

There are eleven meanders on each side with two different spring constants $\mathrm{k}_{1}$ and $\mathrm{k}_{2}$. $\mathrm{K}_{\mathrm{m}}$ is the mean spring constant and it can be expressed as:

$\frac{1}{k_{m}}=\frac{6}{k_{1}}+\frac{5}{k_{2}}$

The total effective spring constant (keff) of the actuation structure can be expressed as:

$K_{\text {eff }}=2 K_{m}$

Here the mean spring constant $\mathrm{k}_{\mathrm{m}}$ is multiplied by 2 because the structure consists of two meanders on two sides.

Table 2: Dimensions of Meanders

\begin{tabular}{lccc}
\hline Type & Length $(\mu \mathrm{m})$ & Thickness $(\mu \mathrm{m})$ & Width $(\mu \mathrm{m})$ \\
\hline $\mathrm{K}_{1}$ & 8 & 1 & 2 \\
$\mathrm{~K}_{2}$ & 40 & 1 & 2 \\
\hline
\end{tabular}

\section{Capacitance ratio}

The capacitance ratio is the ratio of un-actuated to actuated state is given as

$C_{\text {ratio }}=\frac{C_{\text {down }}}{C_{\text {up }}}$

Where $\mathrm{C}_{\text {down }}$ is the capacitance in down state and $\mathrm{C}_{\text {up }}$ is the capacitance in upstate.

$C_{\text {down }}=\frac{\epsilon_{0} \epsilon_{r} A}{t_{d}}$

$C_{u p}=\frac{\epsilon_{0} A}{g_{0}+t_{d}}+c_{r}$

where $\mathrm{A}$ is the effective area, $\epsilon_{r}$ is the dielectric constant, $\epsilon_{0}$ is the permittivity of free space, $t_{d}$ is the thickness of the dielectric, $g_{0}$ is the gap between the dielectric and bridge, $c_{r}$ is the fringing field capacitance. Mainly the capacitance ratio depends on the dielectric material and gap between dielectric layer and deforming structure.

\section{Switching time}

It is the time taken by the switch to toggle from one state to another. Hence, it is one of the most important parameters for the analysis of function of a switch. Switching time is directly proportional to the pull in voltage, inversely proportional to the source voltage and resonant frequency. Low pull in voltage results less switching time. $t_{s}=3.67 \frac{V_{p}}{V_{s} w_{0}}$

Where $V_{P}$ is pull in voltage, $w_{0}$ is resonant frequency and $V_{s}$ is source voltage of the switch.

$w_{0}=\sqrt{\frac{k_{e f f}}{m}}$

Where the effective spring constant is $k_{e f f}$ and $\mathrm{m}$ is the mass of the beam.

\section{Results and discussions}

The shunt switch performance parameters (mechanical and electrical) are calculated by using COMSOL tool and RF characteristics are calculated using HFSS software. An electrostatic actuation voltage of $4.5 \mathrm{~V}$ is applied between membrane and actuation electrodes. The voltage causes the bridge to touch the dielectric and the switch is OFF. There will be a uniform displacement of the membrane with the applied voltage. The total displacement of the switch with a pull in voltage of $4.5 \mathrm{~V}$ is shown in Fig. 5. Theoretically the pull in voltage of the designed switch is $3.6 \mathrm{~V}$ for a calculated spring constant of $0.867 \mathrm{~N} / \mathrm{m}$ and practically the pull in voltage is $4.5 \mathrm{~V}$. There is a slight difference in the theoretical and practical values ofpull in voltage.

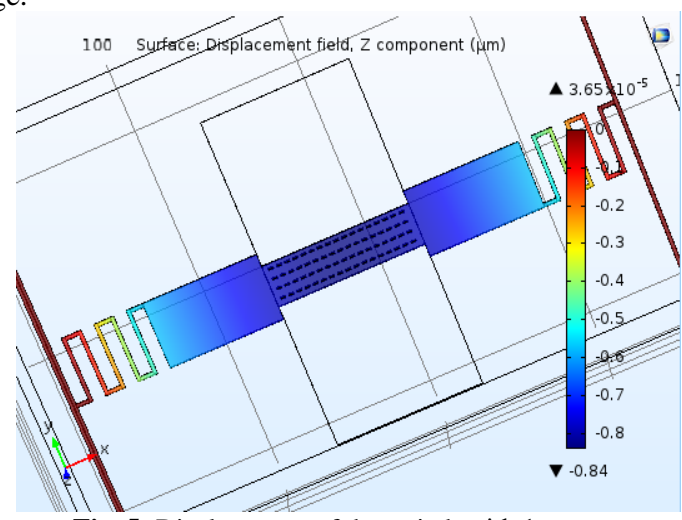

Fig. 5: Displacement of the switch with $1 \mu \mathrm{m}$ gap

The displacement of the switch is $0.84 \mu \mathrm{m}$ towards the dielectric for a pull in voltage of $4.5 \mathrm{~V}$. This is the maximum distance the beam has displaced for an air gap of $1 \mu \mathrm{m}$. The displacement of the switch is also observed with air gap of $2 \mu \mathrm{m}$ and $3 \mu \mathrm{m}$. In both the cases the beam showed a good displacement of $-1.31 \mu \mathrm{m}$ for an air gap of $2 \mu \mathrm{m}$ and $-2.62 \mu \mathrm{m}$ for an air gap of $3 \mu \mathrm{m}$. The displacement of the switch with an air gap of $2 \mu \mathrm{m}$ and $3 \mu \mathrm{m}$ are shown in Fig 6 and Fig 7.

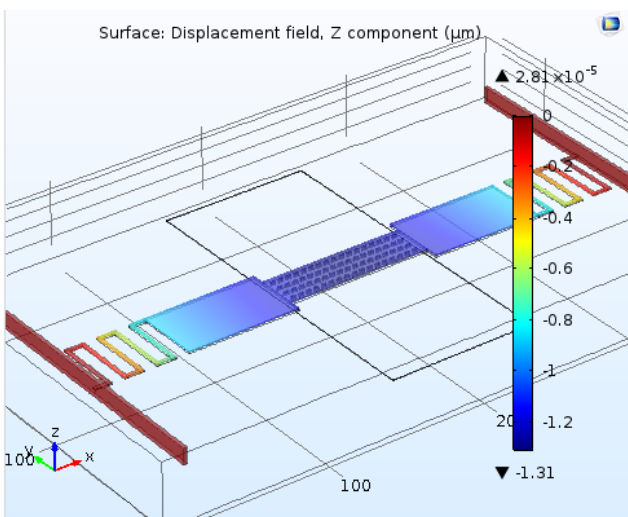

Fig. 6: Displacement of switch with $2 \mu \mathrm{m}$ gap 


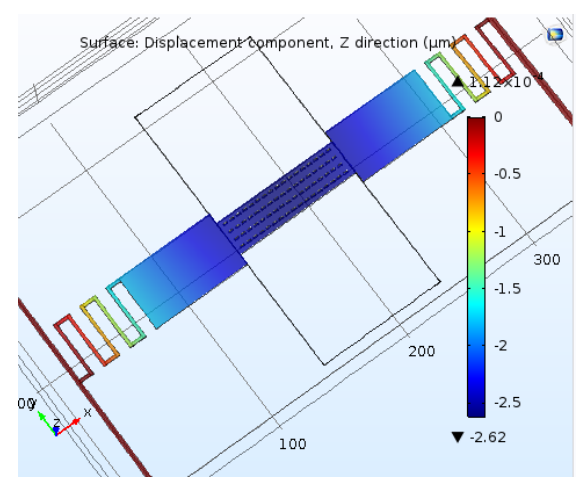

Fig. 7: Displacement of switch with $3 \mu \mathrm{m}$ gap

The beam bends with the applied voltage. The displacement of the beam with respect to the voltage applied is shown in Fig 8 .

The graph shows that the displacement of the switch increases with increase in voltage. As the beam bends downwards, the displacement is negative. The displacement is proportional to the applied voltage.

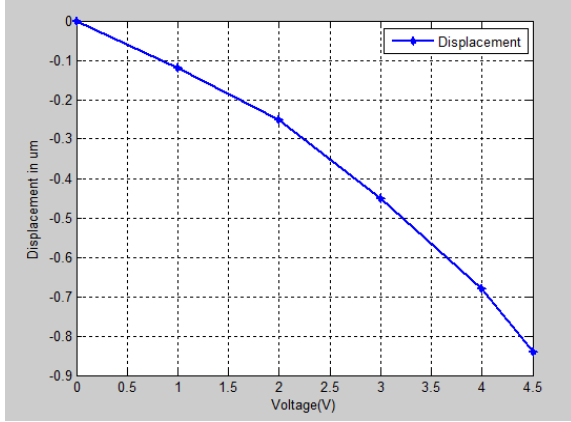

Fig. 8: Voltage vs Displacement graph $(1 \mu \mathrm{m}$ gap $)$

The $\mathrm{S}_{11}$ (Return loss), $\mathrm{S}_{12}$ (Insertion) losses in up position and $\mathrm{S}_{21}$ (Isolation) in down position for the designed switch is measured using AnsoftHFSS 13. The $\mathrm{S}$ - parameters for the proposed switch is feasible for $\mathrm{X}$ band and $\mathrm{Ku}$ band applications. At up state, $S_{11}$ is below $-8.5 \mathrm{~dB}$ for frequency range up to $18 \mathrm{GHz}$ shown in Fig.9, in down state $S_{11}$ is about $-13.50 \mathrm{~dB}$ at $20 \mathrm{GHz}$ shown in Fig 10. Fig.11 shows the insertion lossat $5 \mathrm{GHz}$. At down position $S_{21}$, the maximum isolation of the switch is $-36 \mathrm{~dB}$ obtained at frequency of $5 \mathrm{GHz}$ (Fig 12). Comparisons of the previous work and proposed work is shown below in Table 3 .

Table 3: Comparison of the Designed Switch with Previous Designs

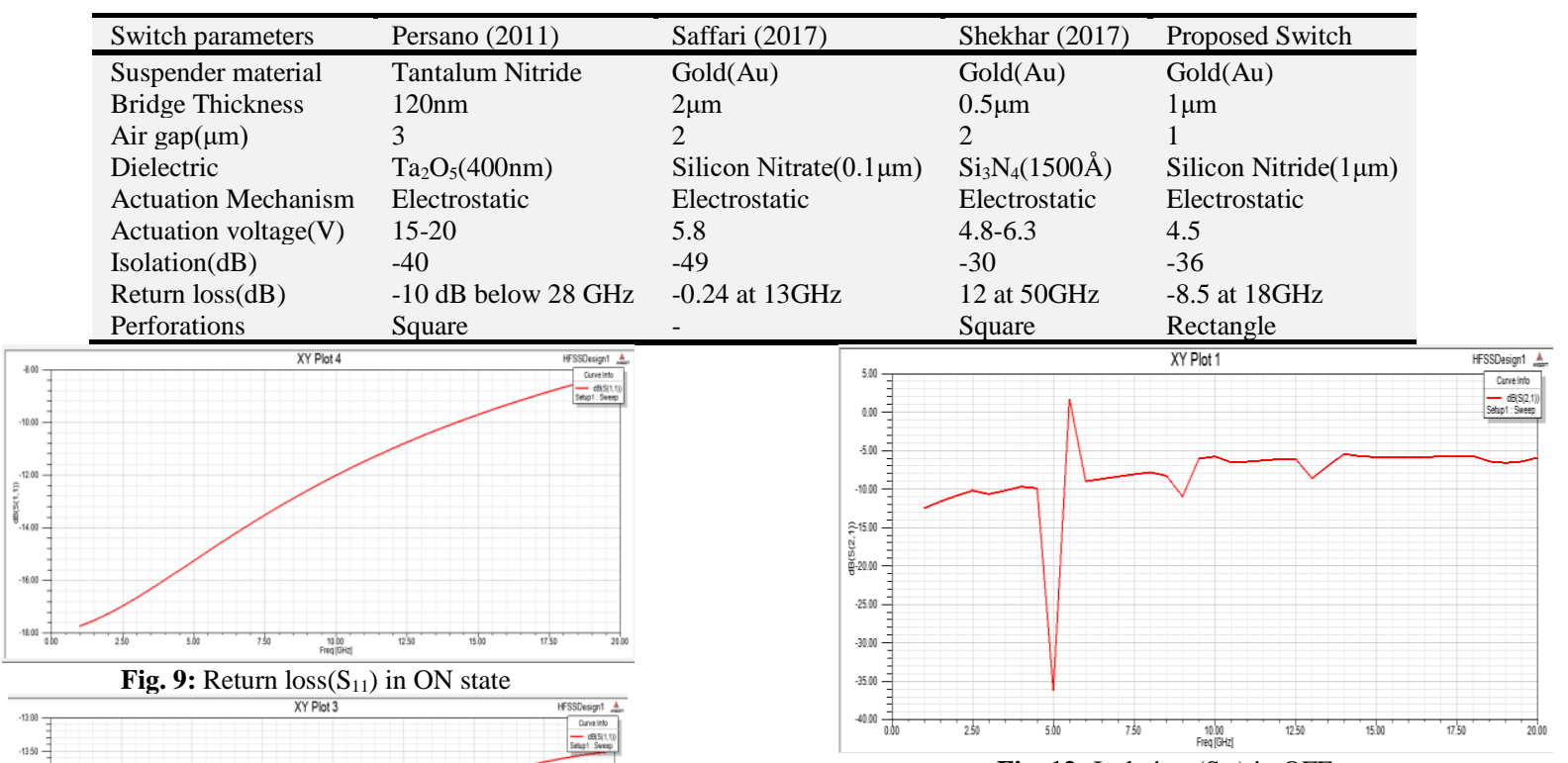

Fig. 12: Isolation $\left(S_{21}\right)$ in OFF state

\section{Conclusion}

In this paper a low actuation voltage RF MEMS shunt capacitive switch is designed and simulated using COMSOL Multiphysics 5.2 software. Low actuation voltage is obtained by decreasing the air gap, spring constant and increasing the actuation area. The designed switch has an air gap of $1 \mu \mathrm{m}$. The beam structure used in the design is serpentine meander structure with a spring constant of $0.867 \mathrm{~N} / \mathrm{m}$. With reduction in these parameters, the pull-in voltage is reduced to $4.5 \mathrm{~V}$ for a displacement of $0.84 \mu \mathrm{m}$. Rectangular perforations are used on the actuation structure to reduce the mass of the switch. Gold material is used in the design of beam and CPW lines because of its high conductivity. The RF performance of the switch is analyzed in An soft HFSS 13 and the results show that the return loss was about $-13.50 \mathrm{~dB}$ at $20 \mathrm{GHz}$ in the OFF state and $-8.5 \mathrm{~dB}$ at $18 \mathrm{GHz}$ in the on state. A high isolation of $-36.00 \mathrm{~dB}$ at $5 \mathrm{GHz}$ was achieved in the OFF state and a low insertion loss is obtained. The results show that the switch is useful for wireless applications operating in the frequency range from 5 to $20 \mathrm{GHz}$. 


\section{References}

[1] Rebeiz G, RF MEMS Theory, Design, and Technology, New York: Wiley, (2003)

[2] Persano A, Cola A, De Angelis G, Taurino A, Siciliano P \& Quaranta F, "Capacitive RF MEMS switches with tantalum-based materials", J. Microelectromech. Syst., Vol.20, No.2, (2011), pp.365-370, 2011

[3] Shekhar S \& Vinoy KJ, "Surface-Micromachined capacitive RF Switches with low actuation voltage and steady contact", Journal of Microelectromechanical systems, (2017).

[4] Saffari H, Moghadam RA \& Tahmasebipour M, "Low actuation voltage RF MEMS Shunt Capacitive Switch based on rotated serpentine spring", Iranian Conference on Electrical Engineering (ICEE), (2017), pp.293-297.

[5] Saxena A \& Agrawal VK, "Comparative study of perforated RF MEMS Switch", 3rd International Conference on Recent Trends in Computing, (2015).

[6] Chaurasia AK \& Mehra R, "Design and Performance Analysis of Capacitive RF MEMS Switch for Low Voltage Reconfigurable Antennas", International Journal of IT, Engineering and Applied Sciences Research (IJIEASR), Vol.3, No.9, (2014).

[7] Balaji K \& Baranichandar K, "Design and Analysis of MEMS Switch for RF Applications", International Journal of scientific research and management (IJSRM), Vol.3, No.1, (2015).

[8] Rebeiz GM, "RF MEMS Switches: Status of the Technology", International conference on solid state sensors, Actuators and microsystems, (2003).

[9] Lakshmi Narayana T, GirijaSravani K \& Srinivasa Rao K, "Design and analysis of CPW based shunt capacitive RF MEMS switch", Cogent Engineering, Vol.4, No.1, (2017).

[10] Saxena A \& Agrawal VK, "RF MEMS Perforated Shunt Switch Design on Hafnium Oxide Substrate for Low Actuation Voltage", International Journal of Electronics and Electrical Engineering, Vol. 4, No. 6, (2016).

[11] Kulkarni SG, "A Novel Design of Cantilever RF MEMS Series Switch", IOSR Journal of Electronics and Communication Engineering (IOSR-JECE), Vol.10, No.3, (2015).

[12] Kaur R, Tripathi CC \& Kumar D, "Low Voltage Rf Mems Capacitive Shunt Switches", Wireless PersCommun, Vol.78,(2014), pp.1391-1401.

[13] Peroulis D, Pacheco SP, Sarabandi K \& Katehi LP, "Electromechanical considerations in developing low-voltage RF MEMS switches", IEEE Transactions on microwave theory and techniques, Vol.51, No.1,(2003), pp.259-270.

[14] Sharma A, Shah A \& Bharti R, "Design \& Simulation of Low Actuation Voltage Perforated Shunt RF MEMS Switch", International Journal of Engineering and Technical Research (IJETR), Vol.3, No.6, (2015)

[15] Manivannan M, JosephDaniel R \& Sumangala K, "Low Actuation Voltage RF MEMS Swi tch Using Varying Section Composite Fixed-Fixed Beam", International Journal of Microwave Science and Technology, (2014).

[16] Molaei S \& Ganji BA, "Design and simulation of a novel RF MEMS shunt capacitive switch with low actuation voltage and high isolation", Microsystem Technologies, Vol.23, No.6,(2017), pp.1907-1912.

[17] Rao KS, Prakash MD \& Thalluri LN, "Cantilever and circular disc structure based capacitive shunt RF MEMS switches", International Conference on Electrical, Electronics, Communication, Computer and Optimization Techniques (ICEECCOT), (2016), pp.336-338.

[18] Sarkar S \& Vimala Juliet A, "Design of a Low Voltage RF MEMS Capacitive Switch with Low Spring Constant", International Journal of Advanced Research in Electrical, Electronics and Instrumentation Engineering, Vol.3, No.4, (2014).

[19] Raman R, Shanmuganantham T \& Sindhanaiselvi D, "Analysis of RF MEMS Series Switch with Serpentine Spring Shaped Cantilever Beam for Wireless Applications", PMME, (2016).

[20] Singh T, Khaira N \& Sengar J, "A novel capacitive RF MEMS switch design for low voltage applications", Fourth International Conference on Computing, Communications and Networking Technologies (ICCCNT), (2013), pp.1-6.

[21] Rebeiz GM \& Muldavin JB, "RF MEMS switches and switch circuits", IEEE Microwave magazine, Vol.2, No.4,(2001), pp.5971. 